\title{
SHORT RATE EXPECTATIONS, TERM PREMIUMS, AND CENTRAL BANK USE OF DERIVATIVES TO REDUCE POLICY UNCERTAINTY
}

\author{
P. A. Tinsley* \\ version: September 1998
}

\begin{abstract}
The term structure of interest rates is the primary transmission channel of monetary policy. Under the expectations hypothesis, anticipated settings of the short-term interest rate controlled by the central bank are the main determinants of nominal bond rates. Historical experience suggests that bond rates may remain relatively high even if the short-term interest rate is reduced to zero, in part due to term premiums reflecting uncertainty about future policy. Term spreads due to policy uncertainty may be reduced by central bank trading desk options that provide insurance against future deviations from an announced interest rate policy.
\end{abstract}

Keywords: bond options, nominal rate zero bound, term premiums.

JEL classification: E4, E5

*Federal Reserve Board, Washington, D.C. 20551; after September 1998: Faculty of Economics and Politics, University of Cambridge, Cambridge CB3 9DD, United Kingdom, ptinsley@econ.cam.ac.uk. Views presented are those of the author and do not necessarily represent those of the Board of Governors or staff of the Federal Reserve System. My thanks for the comments of G. Duffee, D. Kohn, and C. Thomas. 
The term structure of interest rates is the primary transmission channel of monetary policy. Under the assumption that policy actions are summarized by movements in the one-period short rate, policy transmissions to the real economy are influenced more by market perceptions of monetary policy than by the current actions of the central bank trading desk in the spot market for the short rate.

The main subject of this paper is the role of market perceptions of policy when expectations of long-term inflation are low and, consequently, the average level of nominal interest rates is significantly lower than the level of postwar rates. In critical episodes, such as a persistent recession where the short rate may be driven near zero, historical experience suggests long-term bond rates may remain well above zero. This paper indicates derivative securities issued by the trading desk may tighten connections between policy intentions for the short rate and current long-term interest rates. Discussion is directed principally at policy options to influence nominal yields on Treasury securities.

Market perceptions embedded in long-term bond rates include both averages of expected future short-term rates and uncertainty about future policy responses, which is priced in the term premium components of bond rates. Market short rate forecasts and variances are based on conjectured or average-history descriptions of future policy. In the case of the latter, estimated policy response functions help agents to quantify representative policy responses to current and future events. Data-based characterizations of policy range from reduced-form time series models of the short rate to structural feedback rules, such as the calibrated example of Taylor (1993), where future short rate responses are conditioned on forecast indicators of the economy such as inflation and output deviations from trend. Because policymakers are subject to the same difficulties in forecasting future states of the economy as are private sector agents, it is usually unrealistic for policymakers to make unconditional forecasts of their future actions.

However, in times of unusual economic stress, policymakers may wish to consider policy use of more explicit contingent contracts in order to transmit unambiguous signals to markets regarding the direction and volatility of the policy-controlled short rate over a near-term horizon of some consequential length, say one or two years. Examples of such instances include episodes of unusual excess or deficient demand that require a departure from average-history policies, such as initiated in October 1979, and assurance to private sectors of a sustained central bank commitment to significant tightening or loosening of borrowing rates.

The fundamental assumption of this discussion is that complete information on future policy actions is not known, and agents are forced to make probabilistic judgments about future policy. This differs from the standard assumption in macroeconomics of model-consistent or "rational" expectations where private agents and policymakers share the same conditional information, 
including valid structural descriptions of the economy and government policies. ${ }^{1}$ Even if a forward policy is announced by the central bank, it is assumed that such an announcement will be discounted as "cheap talk" given the potential for future policy reversals.

There are two major differences in the present proposal from current operating procedures. First, instead of disclosing only the current policy setting of the short-term rate, the central bank also indicates one or more explicit upper or lower boundary points on the yield curve that will be enforced by future policy, presumably at the short end of the term structure. Second, the credibility of the central bank policy is enforced by binding contractual arrangements with private sector agents, who will be compensated for any future deviations from the policy terms designated in the contingent contracts.

The remaining discussion is organized as follows: Section I briefly discusses empirical evidence on the importance of long-maturity real rates, as opposed to the short-term real rate, as the primary transmission conduit of monetary policy to real economic activity. Discussion then documents that sizeable spreads can exist between the short rate and bond rates, even when the former is near zero. Without a model of agent expectations, it is impossible to determine the extent to which term spreads represent expectations of nonzero short-term rates in future periods or uncertainty about future short rates, as captured in the bond rate term premiums. Section II reviews bond rate forecasts from three alternative small models of monthly economic activity. Each model contains an average-history description of short rate policy. Historical bond rates are parsed into estimates of expected short rates and residual estimates of term premiums. One model is shown to imply theory-based term premium constructions that more closely match the corresponding residual estimates of bond rate term premiums. The parameters of this model can be used to formulate closed forms of simple option contracts. Section III briefly discusses issues in representing market expectations and term premiums that are omitted in certainty-equivalent simulations of macroeconomic models and are consequential when nominal short rates are near or at zero. Section IV discusses policy use of contingent securities directed at lowering bond rates, in part by reducing market uncertainty regarding the short rate intentions of the central bank. Section V concludes.

\section{The Macroeconomic Transmission Effects of Long-Term Interest Rates}

It is often convenient to select a single interest rate or interest rate spread to summarize the effects of monetary policy on aggregate demand. However, there is surprisingly little empirical work to

\footnotetext{
${ }^{1}$ The paper also departs from the standard use in macroeconomic model simulations of certainty-equivalent forecasts which ignore interactions of conditional means and variances.
} 
suggest which rate maturity, or maturities, best capture the aggregate demand effects of monetary policy. Although the short-term interest rate may be useful as a simple summary of monetary policy responses, as suggested by Bernanke and Blinder (1992), the initial portion of this section indicates that the short rate is not a reliable indicator of the transmission effects of monetary policy on aggregate demand.

The remainder of the section notes that, historically, intermediate- and long-term bond rates have remained substantially above zero when the short nominal rate is near or at zero. ${ }^{2}$ Thus, it appears that moving the short rate to the zero boundary is not sufficient to lower bond rates near zero, even in the case of a severe depression in economic activity. Because bond rates dominate the short rate as more reliable indicators of the transmission effects of monetary policy, the consequence of elevated long rates is to muffle the countercyclical efforts of the central bank.

\section{Selecting a benchmark indicator of the aggregate demand effects of monetary policy.}

Given frictions, such as transactions costs and contractual agreements, the effective planning horizons for economic decisions to consume or invest extend over many years. In principle, the entire term structure of real interest rates is relevant in assessing the present value of utility or profits associated with plans for aggregate real expenditures.

However, it is often convenient to select a single maturity rate as a benchmark indicator of the transmission effects of monetary policy on aggregate demand. Table 1 presents results of using three alternative ex ante real rates as the benchmark real rate in an aggregate demand schedule. In the monthly regressions reported in Table 1, the dependent variable is output deviations from trend, represented by the capacity utilization rate of manufacturing. The candidate regressors are: $\rho_{1, t}$, the 1-month rate; $\rho_{60, t}$, the 5-year bond rate; and $\rho_{120, t}$, the 10-year bond rate. Each real rate requires an estimate of expected inflation over the relevant maturity horizon. For example, the 5-year ex ante real rate, $\rho_{60, t} \equiv r_{60, t}-E_{t} \pi_{60, t}$, requires an estimate of the expected 5-year inflation rate, $E_{t} \pi_{60, t}$. Expected inflation rates are constructed by a VAR model approximation of agent expectations, discussed in the next section. The sample span is $1967 \mathrm{~m} 1-1997 \mathrm{~m} 9$, and six lags are used for each regressor.

Table 1 suggests that either the 10-year or the 5-year real bond rate is a better benchmark indicator of the effect of monetary policy on aggregate demand than the 1-month real rate. The first equation shown in Table 1 indicates the level of the 1-month real rate $\rho_{1}$, is not significant.

\footnotetext{
${ }^{2}$ Discussion in this paper is confined to yields on Treasury securities. The intent is to focus on implications of unpredictable monetary policy for interest rate term premiums, abstracting from additional countercyclical movements in corporate bond term premiums that reflect the risk of bankruptcy.
} 
The second and fourth equations in Table 1 show that both the 5-year rate, $\rho_{60, t}$, and the 10-year rate, $\rho_{120, t}$, are significant determinants of cyclical deviations in output. ${ }^{3}$ The third and fifth equations in Table 1 indicate that term spreads from the 1-month real rate are not significant when added to equations already containing the level of either the 5-year or 10 -year real bond rates. ${ }^{4}$

\section{Historical behavior of bond rates when the short rate is near zero}

Of course, observation of the current short rate is not sufficient to determine current long-term bond rates. For zero-coupon bonds, an expectation-based interpretation of long-term bond rates contains two ingredients, an average of expected short rates over the maturity of the bond and the term premium. Thus, the $\log$ yield to maturity on an $n$-period bond, $r_{n, t}$, may be represented as

$$
r_{n, t}=\frac{1}{n} \sum_{i=0}^{n-1} E_{t} r_{1, t+i}+\theta_{n, t},
$$

where $E_{t}$ denotes expectations at the beginning of period $t ; r_{1, t+i}$ is the short rate in the $i$ th month of the forecast horizon; and $\theta_{n, t}$ is the term premium required by agents to compensate for the covariation of bond rates with future states of the economy.

Even in historical episodes where the short rate might be expected to remain near a given level for some extended horizon, spreads between short- and long-term rates appear to be nontrivial. One example is when short-term rates approached zero in the mid-1930s. Whereas U.S. short-term interest rates remained below 1\% from March 1933 through January 1937, reaching a low of 0.25\% in mid-1935, yields on U.S. railroad bonds ranged from about 5.5\% in March 1933 to 3.8\% in January 1937 , and were $4.1 \%$ in mid-1935. ${ }^{5}$ Discussion in Macaulay (1938, p.78) indicates that the minimum maturity of the railroad bonds used was fourteen years.

Selecting a single year for snapshots of annual yields by asset maturity, the 3-month Treasury rate was $.14 \%$ in 1935 , whereas yields to maturity for that same year were $2.79 \%$ for an

\footnotetext{
${ }^{3}$ The capacity utilization rate of manufacturing is stationary, suggesting that the mean utilization rate is the equilibrium or preferred rate of utilization. The associated equilibrium real rates for the 5-year and 10-year rates are listed in the last column of Table 1. These are the real rate levels associated with trend output growth when the utilization rate is at its preferred level. No adjustment has been made for the effects of tax deductibility of interest costs so these equilibrium rates are higher than those associated with equilibrium after-tax real rates.

${ }^{4}$ The last two equations in Table 1 suggest that the 5 -year real bond rate dominates the 10 -year real bond rate as a benchmark indicator of monetary policy, at least when the manufacturing utilization rate is used as the proxy for aggregate output deviations from trend. The spread between the 5-year and 10-year rates is significant when added to the equation containing the level of the 10 -year rate, but is statistically insignificant when added to the equation containing the 5-year bond rate.

${ }^{5}$ The short-term rate is the call money rate (column 1 ) and the railroad bond yields are an index of yields to maturity (column 4) in Table 10 of Macaulay (1938).
} 
unweighted average of outstanding U.S. government bonds due or callable after 15 years, and $1.05 \%, 2.37 \%$, and $3.00 \%$ for corporate bonds of 1-, 5-, and 10-year maturities. ${ }^{6}$

Five years later, corporate spreads over the bill rate were reduced by about another 100 basis points in 1940, when the average 3-month Treasury rate was driven to 1 basis point, Bureau of Census (1975). Indeed, as noted by Friedman and Schwartz (1963), the Treasury bill rate was driven below zero in $1940 .^{7}$

Unfortunately, it is impossible to know whether the non-negligible term spreads that remain when the short rate is near, at, or even below zero are due to expectations of a rebound in the short rate or term premiums reflecting, in part, uncertainty about the short rate intentions of monetary policy. The next section considers three alternative models to represent agent expectations.

\section{Alternative Models of Expected Short Rates and Term Premiums ${ }^{8}$}

Three small VAR models of monthly economic activity are considered as proxies for the short rate expectations of agents. Each VAR contains three variables: a one-month nominal interest rate, $r_{1}$, inflation, $\pi_{1}$, and the rate of capacity utilization, $y$. All interest rates referenced in this paper are end-of-month zero-coupon Treasury bond yields. ${ }^{9}$ Monthly inflation is measured by the BEA chain-weighted deflator for personal consumption expenditures, and monthly capacity utilization by the FRB index for manufacturing. Six lags are used for each regressor.

The alternative VAR models differ in assumptions about the long-run interest rate and inflation rate expectations of agents. The fixed endpoints model assumes that both interest rates and inflation rates are stationary and will return, in long-horizon simulations, to their respective sample means. The moving-average endpoint model, by contrast, assumes that the first-differences of interest rates and inflation rates are stationary. As shown in Kozicki and Tinsley (1997), this assumption

\footnotetext{
${ }^{6}$ Series X451, X474, X487-9 in U.S. Bureau of the Census (1975). The CPI inflation rate for 1935 was about 1.4\%.

${ }^{7}$ In principle, positive costs of storing accumulated cash are consistent with negative nominal interest rates on secure assets. "(B)anks presumably sought again to acquire bills. But the supply outside the Federal Reserve was so small that their attempts served only to reduce yields on bills to a level close to zero....Indeed, yields on Treasury bills were occasionally negative in 1940, when their price was bid up by purchasers seeking to convert cash into other assets for short periods to reduce tax liability under personal property tax laws." Friedman and Schwartz (1963, p. 539). See also Cecchetti (1988) for a discussion of constraints on Treasury coupon bonds that induced negative yields as the bonds approached maturity.

${ }^{8}$ Material in this section is drawn from Kozicki and Tinsley (1998).

${ }^{9}$ Interest rates for 1960m1-1991m1 are from McCulloch and Kwon (1993). For comparability, these data were extended to $1997 \mathrm{~m} 9$ by applying the cubic spline estimator described in McCulloch (1975) to end-of-month yields. My thanks to Mark Fisher for his generous assistance.
} 
implies that long-horizon forecasts of interest rates and inflation rates will converge to weighted moving averages of recent experience. Both of these models are standard alternative specifications in time series modeling. Generally, aggregate postwar data are not able to make a strong case against either the assumption that the short-term interest rate and inflation rate are stationary or the assumption that they are difference-stationary. However, as shown shortly, the difference in dynamic specifications is very consequential for long-horizon simulations, such as required for expectations of long-maturity bond rates.

The shifting endpoints model is nonstandard. This model was developed to represent nonstationary agent expectations associated with episodic shifts in monetary policy. ${ }^{10}$ A common element of the long-run forecasts of the interest and inflation rates is shifting private sector perceptions of the inflation target of the central bank. Learning by agents is nonlinear but generally slow, with average lags of 4-5 years in discerning shifts in the inflation target of monetary policy. Details on the specifications of the shifting endpoint movements of the interest rate and inflation rate are discussed in Kozicki and Tinsley (1998).

Monthly predictions of 10-year bond rates by the three VAR models are shown in Figure 1. The influential roles of the alternative endpoint specifications are apparent. In the top panel, the effect of the fixed endpoints for variables is that the forecast movements of the 10-year bond rate are excessively damped relative to historical movements. Conversely, in the middle panel, the problem is reversed where the predicted 10-year bond rate is more volatile than the historical series, because the endpoint of the short-term nominal rate is a weighted moving average of recent movements in the short rate. By contrast, the bottom panel of Figure 1 indicates that movements of the 10-year bond rate predicted by the shifting endpoints model most closely track the contours of the historical series.

Residual estimates of the term premium for 10-year bond rates are provided by the difference between the historical bond rates and the VAR model predictions, which are simple averages of the predicted short rates over a 120-month forecast horizon. The difference between the true, unobserved term premium, $\theta_{n, t}$, and the residual estimates of the term premium generated by a given VAR model, $\theta_{n, t}^{R}$, is the error in specifying the true model of market expectations.

$$
\begin{aligned}
\hat{\theta}_{n, t}^{R} & =r_{n, t}-(1 / n) \sum_{i=0}^{n-1} \hat{r}_{1, t+i} \\
& =\left[(1 / n) \sum_{i=0}^{n-1} E_{t} r_{1, t+i}-(1 / n) \sum_{i=0}^{n-1} \hat{r}_{1, t+i}\right]+\theta_{n, t},
\end{aligned}
$$

\footnotetext{
${ }^{10} \mathrm{~A}$ quarterly version of this model is incorporated in the staff model, FRB/US, to represent VAR expectations, Kozicki, Reifschneider, and Tinsley (1996).
} 
where $\hat{r}_{1, t+i}$ denotes a VAR model forecast at the beginning of period $t$ of the short rate in the $i$ th period of the forecast horizon. The second line in equation (2) is obtained by replacing the observed n-period bond rate, $r_{n, t}$, by the true (unobserved) model of the bond rate from equation (1). If empirical short rate forecasts of a VAR model do not replicate market expectations, equation (2) indicates that the residual estimates of the term premium generated by that model will contain a potentially large component of specification error, in addition to the actual term premium, $\theta_{n, t}$.

It is apparent from the three panels in Figure 1 that time variation in residual estimates of term premiums depends critically on the particular specification of the VAR used to proxy market expectations. The top panel, generated by the fixed endpoints VAR, suggests that almost all of the variation in bond yields comes from temporal variation in the term premiums. By contrast, in the middle panel of Figure 1, the long-average predictions by the moving average endpoints model closely track the recent history of the short rate. Because actual bond rates are smoother than the short rate, this model suggests term premiums vary considerably in a countercyclical fashion. In particular, the residual term premiums estimated by the moving average endpoints model vary with the long-short yield spread. Finally, the predictions in the third panel of Figure 1, generated by the shifting endpoints model, suggest that the lion's share of historical movements in yields reflects changing market expectations for future short rates. Thus, the shifting endpoints VAR model appears to suggest a more reliable connection between movements in the policy-controlled short rate and movements in a representative bond rate than do the other two VAR models.

In principle, any of the three VAR models may be valid representations of agent expectations. Kozicki and Tinsley (1998) present evidence that the expectations of long-horizon inflation generated by the shifting endpoints model are closest to available survey estimates of expected inflation.

An additional selection standard is to determine if the residual estimates of the term premiums generated by each VAR model are consistent with a coherent theory of the market pricing of interest rate risk. As developed in Kozicki and Tinsley (1998), a theory-based estimate of the term premium will take the form

$$
\hat{\theta}_{n, t}^{T}=\sum_{i=0}^{n-1} \hat{w}_{t+i} \hat{\sigma}_{r, t+i}^{2},
$$

where $\hat{\sigma}_{r, t+i}^{2}$ denotes the estimated conditional variance of the short-term interest rate in period $t+i$, and the weights, $\hat{w}_{t+i}$, are functions of the estimated parameters of the relevant VAR and an unobserved parameter, $\beta$, associated with the risk aversion of agents.

Note that even if one of the three VAR models provides a close approximation of market expectations, equation (3) will be unable to replicate the time-varying residual estimates of the 
term premiums shown in Figure 1 if the short rate variance is fixed. Thus, an explicit model of the time-varying volatility of the short rate, $\sigma_{r, t+i}^{2}$, is required.

There are two basic approaches to modeling the time-varying variances of variables. One is a shock-based $(\mathrm{GARCH})$ model where conditional volatility is a function of recent shocks to the variable. The other is a level-based model where conditional volatility is a function of the level of the variable. In addition to historical studies associating the level and volatility of inflation, literature linking interest rate standard deviations to the square root of interest rate levels is well-known, including Merton (1973) and Cox, Ingersoll, and Ross (1985).

Table 2 presents several screening regressions where the residual estimates of the term premiums, as shown in Figure 1, are regressed on 1-month predictions of the short rate, $r_{1, t}$. The predicted short rate appears to be a promising explanatory variable, explaining from $25 \%$ to $50 \%$ of monthly variations in the residual term premiums for the shifting and fixed endpoints models, respectively. Predicted short rates do not appear to be a good explanatory regressor for the moving endpoints model for the obvious reason that recent levels of short rates are already captured in the bond rate predictions of this model by the moving average endpoint, as discussed earlier.

Responses of the VAR prediction error variances of the short rate to movements in the level of the short rate are estimated in Table 3. These regression slopes will be used in the construction of theory-based estimates of the term premium, $\theta_{t}^{T}$. Two parameters remain to be determined; the implied variance of the short rate for zero levels of the short rate, $\psi_{0}$, and the market price of risk, $\beta$. These two parameters are selected by matching the mean and variance of the estimated residual term premiums.

The residual-based estimates of the 10 -year bond rate term premiums, $\theta_{t}^{R}$, generated by each of the three VARs and the matching theory-based constructions of the term premiums, $\theta_{t}^{T}$, are compared in Figure 2. If a particular VAR provides a coherent description of agent expectations, the theoretical term premium construction, based on parameters of the VAR, should be roughly aligned with the residual term premium estimated by that VAR model. ${ }^{11}$

As shown in the first panel of Figure 2, the theory-based term premium associated with the fixed endpoints model is quite responsive to movements in the short rate but the timing of these movements do not closely match the residual-based estimate of the term premium generated by this model.

Although timing is improved for the theory-based construction of the term premium of the

\footnotetext{
${ }^{11}$ Due to the small dimensions of the VAR models, one may expect the theoretical term premium constructions to be smoother than the true term premiums. That is, it seems plausible that market agents use a much larger set of macroeconomic indicators to represent the stochastic discount valuation of future returns on financial assets.
} 
moving average model, shown in the second panel of Figure 2, the signs of movements in the theoretical term premium are the reverse of those in the residual term premium. This mirror "reflection" problem is also summarized by the negative sign of the screening regression in Table 2 for the residual term premium of the moving average endpoints model. Essentially, the residual estimate of the term premium in this model must move against swings in the short rate in order to compensate for the exaggerated changes in the nominal rate endpoint imposed by the moving average specification.

The theory-based estimate of the term premium of the shifting endpoints model, in the bottom panel of Figure 2, appears to more successfully match the contours of movements in the associated residual-based estimate of the term premium. ${ }^{12}$

Summarizing results in this section, the shifting endpoints model appears to provide a usable approximation of agent expectations of future short rates, along with an implied theory-based representation of bond rate term premiums. The ability to generate reasonable estimates of both first and second moments of interest rate expectations permits closed-form approximations of other financial market instruments, such as options contracts. As discussed later, derivative securities may be useful not only as market indicators of policy uncertainty but also as potential instruments of stabilization policy. Closed-form representations also enable modelers to explore the economic determinants and signaling effects of these additional market instruments.

\section{Issues in Describing the Behavior of Interest Rates at Zero}

A small, but growing, literature has emerged that uses empirical macroeconomic models to illustrate possible limitations on monetary stabilization policies when nominal interest rates are near or at a zero floor. Recent contributions include Laxton and Prasad (1997), Fuhrer and Madigan (1997), Orphanides and Wieland (1998), and Tetlow and Williams (1998). Partly because each study used one or more different methods to impose the zero floor on nominal interest rates, conclusions are mixed. The two most recent studies suggest the zero lower bound for nominal rates is not a serious constraint for operating policy as long as policy is sufficiently aggressive in offsetting unfavorable shocks or the long-run inflation target remains modestly positive.

Discussion in this section is less optimistic regarding the influence of the zero interest rate boundary on monetary stabilization policies when the average level of interest rates is low, due in part to a more conservative description of the formation of agent expectations. Several issues

\footnotetext{
${ }^{12}$ The theory-based estimate of the term premium is considerably smoother than the residual estimate, suggesting future work might consider a combination of level-based and shock-based estimates of the short rate variance, as in Brener, Harjes, and Kroner (1996).
} 
in representing the effects of the zero bound on nominal rates are discussed that have not been addressed in previous studies. A brief preview of these issues includes:

- Under normal distribution descriptions of interest rates, the zero bound induces a "positive" bias in expected nominal rates as the mode of the interest rate distribution approaches zero. Given the historical volatility of the short rate, this effect can be sizeable and is not captured by deterministic or "certainty-equivalent" simulations.

- Level-based descriptions of volatility imply that this positive bias will also prevent the volatility of the short rate from falling to the level that would be associated with a zero mean expected rate. The effect of a binding lower bound on the nominal short rate necessarily increases the volatility of real activity and inflation.

- Larger perceptions of short rate volatility, due to the indirect effect of a positive bias in expected rates or to increased uncertainty regarding monetary policy during episodes that differ from "average-history" responses, are consistent with the existence of significant term premiums of bond rates even when the current short rate is near zero. ${ }^{13}$

- Methods used by previous studies to impose the zero lower bound on counterfactual simulations of the short rate require departures from average-history descriptions of policy responses, where the departures are specific to the size of shocks to macroeconomic indicators. Consequently, model-consistent or "rational expectations" simulations are likely to overstate the effectiveness of rapidly adapting policies, whose changing response characteristics must be learned by market agents. ${ }^{14}$

In a situation where the current short rate has been driven near zero, whether or not long rates also move appreciably towards zero depends on two perceptions of market agents. The first is whether or not policy will continue to hold the short rate at zero for some extended horizon. The second is the degree of uncertainty agents have regarding policy forecasts. Both perceptions will generally require departures from standard certainty-equivalent and rational expectations descriptions of agent expectations.

\section{The positive zero floor bias in expectations}

Conventional representations of short rate expectations are not relevant if the zero boundary is

\footnotetext{
${ }^{13}$ One experiment briefly discussed in Fuhrer and Madigan (1997) illustrates a relative deterioration in policy effectiveness if the bond rate contains a term premium.

${ }^{14} \mathrm{~A}$ related issue is that many policies suggested as effective in neutralizing the lower bound constraint imply prompt and sizeable policy responses to unfavorable shocks and to forward-looking expectations of future bindings at the zero boundary. Typically, these simulated policies are more aggressive than historical policy responses and are perceived with certainty by both policy makers and agents.
} 
binding. In the case of standard linear feedback rules used to represent short rate responses, several methods have been employed to impose a zero truncation barrier on the certainty equivalent forecast of the short rate and on the subsequent transmission of expected short rates to expected bond rates. ${ }^{15}$

However, in a reasonably wide neighborhood of zero, truncation of certainty-equivalent forecasts does not provide an accurate representation of the expected short rate. The effect of the zero lower boundary on the mean expectation of the short rate is depicted in Figure 3 . For the monthly sample, 1982m10-1997m9, the mean and standard deviation of the 1-month zero coupon rate are 6.06 and 1.80, respectively. The distribution of the short rate that is associated with these moments is depicted by the normal distribution in Figure 3 centered at 6.0. ${ }^{16}$

As the center of the normal distribution moves leftward towards zero, a larger portion of the distribution will extend over negative short rate outcomes. Because the support of the normal distribution runs from $-\infty$ to $+\infty$, a portion of any normal distribution will always lap over into the region of negative interest rates. However, the magnitude of the overlapping density is modest when the center of the distribution is more than two standard deviations above zero.

For comparison, the left-hand distribution in Figure 3 is centered at zero. In this instance, only the right half of the density is relevant in weighting the probabilities of nonnegative outcomes. Here, and in the remainder of the paper, the "+" superscript is used to indicate selection of only positive outcomes. The mean expectation of nonnegative short rates is now $E_{t}\left\{r^{+}\right\}=\left(\frac{2}{\pi}\right)^{\frac{1}{2}} \sigma_{r_{1}} \approx .8 \sigma_{r_{1}}$. where $\sigma_{r_{1}}$ denotes the standard deviation of the short rate. Thus, in the case of $\sigma_{r_{1}}=1.80$, the "bias" of the mean expectation of the short rate for the left-hand distribution is $E_{t}\left\{r^{+}\right\}=1.44 .^{17}$

\section{Alternative combinations of short rate expectations and term premiums}

The specification of level-based volatility, discussed earlier, implies that the positive bias at zero

\footnotetext{
${ }^{15}$ Three alternative methods of imposing the zero lower boundary on the short nominal rate are illustrated in Fuhrer and Madigan (1997).

${ }^{16}$ The common assumption that bond prices are log normally distributed, implies that yield to maturity rates are normally distributed.

${ }^{17}$ For cases where the mode of the normal distribution is nonzero, $\bar{r} \neq 0$, the expectation subject to the zero floor is: $\left.E_{\{} r_{1}^{+}\right\}=\bar{r}+\left(\frac{\phi(-z)}{\Phi(z)}\right) \sigma_{r}$, where $z \equiv \bar{r} / \sigma_{r}$ and $\phi($.$) and \Phi($.$) denote the normal probability density and cumulative$ distribution functions, respectively, vid. Johnson and Kotz (1970). In the examples of this section, the standard deviation used to compute the zero floor bias in expectation does not vary with the level of the rate, in contrast to the levels-based model of volatility used for the term premium. To capture the lower volatility of the short rate in recent years, the standard deviation used to calculate the zero floor bias in expectation is based on the sample after $1982 \mathrm{~m} 9$.
} 
has two potential channels of influence on bond rates, one preventing the weighted average of expected short rates from falling to zero and the other inhibiting reductions in the short rate conditional variance that is priced in the term premium. Effects of nontrivial expectational biases induced by the zero lower bound on these two components of bond rates are illustrated in Table 4 .

The four columns of Table 4 illustrate the consequences for 5-year bond rates, $r_{60, t}$, of alternative market perceptions regarding the behavior of the short rate controlled by the central bank, $r_{1, t}$. The first row indicates alternative assumptions about the current short rate. Initially, we assume these expectations are assumed to persist indefinitely. Using terminology introduced earlier, the values in the first line are also the levels assumed for the long-run endpoint of the nominal 1-month rate. Thus, if the short rate is currently 6 , the nominal rate endpoint is also 6 . Moving to the fourth row of Table 4, the flat expectations of the short rate also imply that the 60-month average of expected short rates is 6.

Continuing with the example in the first column, the standard deviation of the short rate is 1.80 , as shown in the second line. Using the parameters of the shifting endpoints VAR approximation of agent expectations, the estimated term premium for the 5-year bond rate is 2.14 , shown in the fifth line of Table 4. Summing the two components, the 60-month average of first moment expectations and the term premium pricing of the second moment expectations suggests the 5-year rate is 8.04, shown in the sixth row of Table $4 .{ }^{18}$

To illustrate the expectations effect of the zero bound, now consider the corresponding entries in the last column of Table 4. Here, both the certainty-equivalent (zero residuals) forecast of the current 1-month rate and the long-run endpoint of the 1-month rate are zero. However, as indicated in the fourth row, the 60-month average of expected 1-month rates is 1.44 , which reflects the asymmetric (half-normal) distribution of possible 1-month rates over the 60-month forecast horizon. ${ }^{19}$ Looking at the remaining entries in the fourth row of Table 1 , it is apparent that the positive bias introduced by the zero bound is negligible for a short rate distribution centered at 6.0 (the first column), 6 basis points for a distribution centered at 4.0 (the second column), and 45 basis points for a short rate distribution centered at 2.0 (the third column). Returning to the fourth column and again using the parameters from the shifting endpoints VAR, the term premium associated with expected 1-month rates at 1.44 is estimated to be 1.19 , giving a total of 2.63 for

\footnotetext{
${ }^{18} \mathrm{It}$ is encouraging to note that this estimate is close to the $1982 \mathrm{~m} 10-1997 \mathrm{~m} 9$ sample mean of about 7.9 for the zero-coupon 5-year rate. This suggests the term premium model is at least locally scalable for neighboring maturities, even though the model was calibrated to fit only the first two moments of the 10-year bond term premiums.

${ }^{19}$ Under the convention that expectations are calculated at the beginning of the current period, the positive "bias" is also added to the current period forecast in $\mathrm{t}$.
} 
the 5-year rate.

\section{Bond rate implications of a temporary change in the short rate}

Now consider a 1-month departure from standard expectations. This is depicted in the last block of rows in the top half of Table 4 (rows 7-9). At the beginning of the period, the central bank drives the short rate to zero. Because market traders perceive this as a one-time event, the expected first and second moments of short rates in subsequent months revert to "average-history" values, such as the 6.0 and 1.80 assumptions used in the first column. Even in the first month, trader expectations for the remainder of the month are nondeterministic so the variance of the short rate is set equal to the average-history expectation. Consequently, in all four columns, the mean expectation of the 1-month rate in the current month is 1.44 . In the example of the first column,

the 60 -month average is $\frac{59}{60} 6.0+\frac{1}{60} 1.44=5.92$. As might be expected, changes in the short rate that are viewed as transient departures from average-history expectations have little effects on long bond rates. In contrast to results in preceding columns, results in the fourth column are unaltered because the average-history assumption regarding the level of the short rate is already at zero.

\section{Effects of a persistent change in the short rate}

To explore the effects of more persistent expectations regarding changes in the short rate, suppose the economy has entered a period of depressed demand and the central bank wishes to convey to markets a revised policy where the short rate will be held at zero for an extended period, such as 12 or 24 months. As indicated at the beginning of this section, the success of the new zero-rate policy depends on two perceptions of the market: (1) How persistent will be the current short rate setting at zero? (2) What is the probability that the central bank may depart from this policy? Three possible scenarios for agent expectations are shown in the bottom half of Table 4.

The first block of rows in the bottom half of Table 4 (rows 10-12) addresses the issue of agent expectations regarding the persistence of the current policy action. An additional conditioning assumption is the average-history level to which the short rate is assumed to return after the new policy expires. In the first column, the short-rate is expected to revert to the average-history level of 6.0 after the initial 12 months, and the 5-year rate falls from 8.14 to 6.97 . Note that the reduction of the 60-month average of the 1-month rate from 6.0 to 5.09 is smaller than one would expect for a $20 \%$ drop in the level of the 1 -month rate over the 5 -year horizon $(.8 \times 6.0=4.80)$. This is because agents remain uncertain as to possible stochastic departures from the announced target. Although the zero boundary bias is inconsequential at the average-history assumption of a short rate level at 6.0, it kicks in with an expected value of 1.44 at the alternative assumption of 
a short rate level at zero. In other words, agents do not have certainty-equivalent forecasts when the distribution of rate expectations moves closer to the zero boundary. Similar reasoning explains the reductions shown in the rest of this block. Note that nothing is accomplished by the zero-rate policy announcement in the last column because agent expectations remain nondeterministic.

\section{Consequences of reduced policy uncertainty}

Now suppose policy, by some means as yet unexplained, is able to convince market agents that the new policy of zero short rates for 12 months is a certain event. The next block of rows (rows 13-15) indicates that reducing policy uncertainty to zero translates to an additional reduction of about 55 basis points in each of the four columns. The reason for the similarity in reductions is that, in each average-history column, the positive bias at zero in the first twelve months is eliminated (a reduction of 29 basis points) along with elimination of the term premium in the first 12 months (an additional reduction of 26 basis points).

The last block of rows in Table 4 (rows 16-18) illustrates an additional dimension of potential policy communications - the horizon of a persistent alteration in policy. In this example, the certain reduction to zero of the 1-month rate is extended to a 24 -month horizon. In the first column, the 5 -year bond rate is reduced by 341 (8.14 - 4.73) basis points. Even in the case of the last column, where the long-run endpoint of nominal rates is zero, the 5-year bond rate is reduced by 109 (2.63 - 1.54) basis points, a nontrivial reduction of nearly $60 \%$.

As noted earlier, historical bond rates have remained well above zero even when the short rate is near or at zero. This section has indicated that the higher levels of bond rates are due to a combination of expectations of an eventual resumption of the average-history level for the short rate, of which an important determinant is the perceived long-run policy target for inflation, and uncertain expectations regarding the level, volatility, and horizon of the new operating policy for the 1-month rate. Further reductions in bond rates are unlikely to be achieved by conventional operating policies that indicate only the current level of the short rate. Policies aimed at credible enforcement of upper or lower boundaries on segments of the term structure, such as illustrated in Table 4, are discussed in the next section.

\section{Policy Puts}

Although much attention is paid in the financial press to the current policy target for the short rate, the results of section I indicated that bond rates accomplish most of the heavy lifting of monetary policy. Under expectation-based theories of the term structure, bond rates consist of averages of expected short rates and term premiums. In contrast to corporate bond rates where significant 
portions of term premiums are compensation for risks of bankruptcy, term premiums of Treasury securities are principally market valuations of the uncertainty of monetary policy.

In relatively quiescent periods, monetary policy appears to function well by communicating primarily the current setting of the short rate-a single point on the term structure. Market agents also interpret various public communications by the central bank, such as speeches or the historical record of instructions to the trading desk, to infer the most likely paths for future short rates, distributions of possible outcomes about these trajectories, and the policy target for long-run inflation that, ultimately, is the single component controlled by policy that determines the average level of nominal interest rates.

When the level of the short-term interest rate is driven near zero, the standard policy communication channel loses its information content because there is little room left for signaling with the spot short rate. In these instances, it is desirable for the central bank to credibly communicate the outlook for short rates, including the level, volatility, and horizon of the new short rate policy. These characteristics of near-term policy essentially determine the distribution of yields associated with the initial portion of the term structure. In many instances, the central bank aims to offset a large shock or accumulated shocks to demand or supply. Thus, the near-term policy objective is often asymmetric and directed at enforcing an upper or lower boundary on an initial segment of the term structure.

In an episode of depressed demand with the short rate already near or at zero, it is unlikely that long rates with sizeable term premiums will be substantially reduced unless policy is directed at enforcing a floor on the prices of shorter-maturity bonds. In the example of the previous section, policy wishes to persuade traders that prices of bonds with maturities of two years or less will not fall significantly below one. The remainder of this section discusses examples of derivative securities that can be written by the trading desk to communicate a specific policy of asymmetric intentions for future short rates. For simplicity of exposition, the examples will be European puts on Treasury bonds.

\section{Bond puts and interest rate calls}

To enforce a floor on near-term bond maturities, derivative contracts that provide explicit policy signals over the next two years include the writing of short-horizon bond puts. For example, suppose the expiration date of the options is three months, and put contracts are written on forward 9-month and 21-month bonds with a unit strike price of $\$ 1$. In three months, the trading desk will be obligated to buy 9-month and 21-month Treasury bonds from option owners at the strike price of $\$ 1$ or, more likely, will settle in cash the difference between $\$ 1$ and the existent bond prices, 
$0<P_{9, t+2}, P_{21, t+2}<1$. The options will be exercised by market traders if the interest rates on these bonds, $r_{9, t+2}$ and $r_{21, t+2}$, are greater than zero.

For the purpose of public communications regarding policy options, a simple way to interpret the writing of bond puts is that the trading desk is issuing insurance policies against the risk of interest rates rising above zero over the next two years. In the example given, 3-month call options are written, in effect, on the 9-month and 21-month interest rates that will exist in three months. ${ }^{20}$ Before turning to a discussion of broader issues raised by the policy use of derivative securities, it may be useful to review some simple mechanics of the market valuation of European calls on interest rates (or, equivalently, European puts on bonds). ${ }^{21}$

\section{Pricing the interest rate call (bond put)}

As shown at the top of Table 5, and reproduced here, the value of a 3-month call option on the forward 9-month interest rate is

$$
\begin{aligned}
\operatorname{call}_{t}\left(r_{9, t+2}, r_{x}\right) & =E_{t}\left\{M_{t+2}\left(r_{9, t+2}-r_{x}\right)^{+}\right\} \\
& =e^{-r_{3, t} / 400}\left(E_{t}\left\{r_{9, t+2}\right\} N\left(d_{1}\right)-r_{x} N\left(d_{2}\right)\right)
\end{aligned}
$$

where, as before, the "+" superscript selects only positive values between the forward 9-month rate, $r_{9, t+2}$ and the "strike" rate, $r_{x}$. $M_{t+2}$ denotes the stochastic valuation factor which determines the market valuation of income received in $t+2$; its main function is to determine the compensation required by asset holders for covariation of asset income with expected variation in marginal utility such as due to changes in wealth. Turning to the second line in equation (4), the valuation of the call option is seen to be the product of the 3-month discount factor, $e^{-r_{3, t} / 400}$, times a weighted spread between the forward 9-month rate at the date of option expiration and the strike rate. Because $N($.$) denotes the cumulative distribution of the normal distribution, the weights$ range in value from 0 to 1 . The arguments of the cumulative distributions are:

\footnotetext{
${ }^{20}$ The examples are options on forward interest rates at a single point in time. As noted later, the trading desk can write more complex options that insure against average deviations of the short rate from a prescribed trajectory over the next 12 or 24 months.

${ }^{21}$ In discussing the functional use of bond options, it is immaterial whether the bond option is formulated in terms of a strike price, such as the bond put, or in terms of a strike rate, such as the interest rate call. Differences may exist in practice due to expectational assumptions or institutional conventions. For example, the valuation of an option is not invariant to alternative assumptions that the bond price or the bond interest rate is lognormally distributed. Bond options traded in over-the-counter markets are often formulated in interest rate terms, whereas bond options traded in exchanges are often expressed in bond price terms.
} 


$$
\begin{aligned}
& d_{1}=\frac{\log \left(E_{t}\left\{r_{9, t+2}\right\} / r_{x}\right)+0.5 \sigma_{9, t+2}^{2}}{\sigma_{9, t+2}} \\
& d_{2}=d_{1}-\sigma_{9, t+2}
\end{aligned}
$$

where $\sigma_{9, t+2}$ denotes the standard deviation of the log of the forward 9-month rate. ${ }^{22}$

Some illustrations of alternative market valuations of the 3-month call option on the forward 9-month are shown in Table 5. The top half of Table 5 indicates various conditioning assumptions. As in Table 4, four alternative assumptions are made for current agent expectations regarding the 9-month rate that will occur in three months, $t+2$, ranging from 6.0 to a near-zero value of 0.1 .

The initial column in the bottom half of Table 5 lists representative strike rates that could be selected by the writer of the call option. The neighboring $4 \times 4$ array indicates market valuations associated with particular conditioning assumptions about agent expectations (in the top half of Table 5) and the strike rate selected for the option. The small numbers along the main diagonal of this array are "at the money" valuations. That is, even when the forward 9-month rate is expected to exactly match the strike rate, the value of the option is not zero due to perceived short rate uncertainty represented by the standard deviation of the log 9-month rate, $\sigma_{9, t+2} \cdot{ }^{23}$

Moving down each column from the main diagonals, the option is "in the money" when the trader expectation regarding the forward rate is above the relevant strike rate in the option. The option valuation is largest when the option is "deep in the money," such as shown at the bottom of the first column where the mean expected forward rate is 6.0. In this example, the strike rate of 0.1 is sufficiently below the market forward rate expectation that traders are nearly certain that the option will be exercised. Thus, the value of the near-certain option is close to the product of the 3-month discount factor and the spread between the expected forward rate and the strike rate, $.985(6.0-0.1)=5.81$.

\section{Altering fundamentals}

In principle, the existence of well-developed derivatives markets increases the liquidity of asset markets and, thus, tends to reduce bid-ask spreads on underlying assets, Fedenia and Grammatikos (1992). The valuations of derivatives are derived from contingent claims on underlying assets. In

\footnotetext{
${ }^{22}$ This option valuation solution was developed by Black (1976). More refined closed-form solutions for interest rate options are available, such as Miltersen, Sandman, and Sondermann (1997), but equation (4) appears to be commonly referenced for interest rate derivatives, Hull (1997), and avoids imputing densities for negative interest rates.

${ }^{23} \mathrm{An}$ approximation of these valuations is $.4 \sigma_{9, t+2} r_{x}$. A first-order expansion of $N(z)=0.5+(2 \pi)^{-\frac{1}{2}} z$, and the relevant discount factor is given by the fourth line of Table 5.
} 
turn, the values of these assets, such as equities and bonds, are due to the economic fundamentals that determine the present value of expected earnings generated by the relevant corporations or governments that issued the underlying stocks or bonds. Thus, apart from temporary increases in volatility in episodes of large price movements such as October 19, 1987, there is little empirical evidence to support a reliable causal connection between movements in the valuations of options and of underlying assets in the absence of effects of derivatives on economic fundamentals. ${ }^{24}$

By contrast, policy use of derivatives can alter the perceptions of economic fundamentals held by market agents. Given that the central bank has a monopoly on the supply of the domestic currency, it has the capacity to directly purchase or write options against any proportion of the outstanding Treasury debt. Private sector agents who exercise put options written by the trading desk are paid in the domestic currency. ${ }^{25}$

Of course, market expectations can be notoriously difficult to influence. In the case of a put option floor on Treasury bonds, a number of factors may influence the ability of the trading desk to move the bond price towards the selected strike price, especially if the initial bond price is well below the strike price (the bond rate is well above the strike rate). Several issues regarding the operational implementation of policy put options are briefly noted:

It will be difficult for the trading desk to move the bond price up (the bond interest rate down) if the private sector believes the policy could be reversed before the expiration date of the put option. Of course, the more options that are written by the trading desk, the more money would be left on the table if the central bank were to renege on its announced policy of maintaining a low short-term rate for a specified horizon. Ironically, the potential of policy reversals to undercut the expectations effects of policy options is more of a problem for a strong central bank than a weak central bank, if the latter is not able to absorb the large option losses that could accompany a significant policy reversal.

On average, net receipts from market valuations of policy options will be positive if the options provide insurance value for investors against uncertain policy. As indicated in Table 5, less predictable policy is more costly for the private sector to insure against.

To the extent that relative supplies of assets are also a determinant of asset prices, the cash payout of policy options that are unsuccessful in reducing bond rates may have a positive influence

\footnotetext{
${ }^{24}$ Different views on the October 1987 consequences of portfolio insurance based on dynamic trading of stocks are advanced in Hull (1997) and Mullins (1997). The latter also provides a general review of empirical literature on the effects of derivatives on asset markets.

${ }^{25}$ Note that this differs importantly from interventions in international currency markets, where the ability of a central bank to support the price of the domestic currency depends on its initial supply of foreign currencies relative to the monetary base or the cooperation of other central banks.
} 
on bond prices. ${ }^{26}$ In other words, if traders expectations are not consistent with the policy outlook specified in the policy options, bond prices may remain below the option strike prices. The consequence of the cash settlements when the options are exercised is roughly equivalent to a delayed open market operation of government security purchases, also aimed at lowering interest rates. Of course, the extent of interest rate pressure would depend on which assets were subsequently purchased by owners of the exercised options.

Many economists, including Keynes (1930), have suggested that the central bank can operate directly on long bond rates by directly purchasing or selling bonds. ${ }^{27}$ As noted earlier, the effectiveness of such policy actions rests on the imperfect substitutability of portfolio assets. If the private sector is not indifferent to the relative supplies of different bond maturities, the trading desk could duplicate the bond price effects of any particular put option contract by buying a sufficient quantity of outstanding bonds of the appropriate maturities. However, this may require extensive interventions in Treasury markets. Most importantly, like a dedicated behaviorist, the market would have to examine trading desk operations closely to infer the ultimate target objectives of policy. Because traders would not be compensated for subsequent departures from the revised objectives of the trading desk, it seems likely they would be cautious in revising future short rate expectations. By comparison, the objectives of policy regarding future short rates are immediately transparent to traders from the explicit terms of the put options, as illustrated above.

Further, as noted by Merton (1995), an additional possible advantage of policy options is that they may continue to automatically work against unexpected shocks, without waiting for subsequent interventions by the trading desk. In the case of policy bond puts, option purchasers may conduct "delta" hedging to maintain a given level of risk exposure for their portfolios. If an unexpected shock serves to drive down the price of the bond of the maturity specified in the option, the value of the option rises (that is, the bond interest rate is higher). Since this increases the likelihood of exercising the option, the owners of the option will increase their holding of bonds to offset the larger delta (in absolute value) of the put option. Similarly, option owners will decrease the amount of bonds in their portfolios if a shock increases the relevant bond prices. These actions have the same stabilizing effects on the relevant bond prices as if the central bank trading desk were to buy or sell bonds of the appropriate maturities. In effect, owners of the options who

\footnotetext{
${ }^{26}$ The primary policy transmission channel emphasized in this paper is that current central bank actions affect trader expectations about future short rates. A second channel sometimes advanced to explain direct effects of trading desk purchases is that alternative financial assets, including currency, are imperfect portfolio substitutes so the price of an asset is expected to move inversely to its aggregate supply.

27 “'It should not be beyond the power of a Central Bank (international complications aside) to bring the long-term market-rate of interest to any figure at which it is itself prepared to buy long-term securities." Keynes (1930, p.371)
} 
conduct delta hedges are delegated agents of the trading desk.

Although there can be some shock value in destroying the relevance of prevailing expectations by sudden introductions of new policy instruments and objectives during crises, as occurred in October 1979, the probability of successful executions of policy options would most likely be higher if all participants, both the trading desk and asset markets, had prior experiences with policy use of options to supplement conventional policy trading. As an example, the trading desk could write derivatives, such as average rate collars, that would insure option owners against short rate deviations from an announced policy range in intervals between FOMC meetings. If a mix of conventional trading and policy options were routinely familiar, it seems likely that when the economy is confronted by episodes where conventional policy operations are likely to be ineffectual, a shift in the operational policy mix towards more reliance on options would be viewed as a sensible, if not anticipated, alteration of policy operations.

Finally, at a minimum, explicit policy options provide a transparent, market-based index of the credibility of the particular policy scenario embedded in the terms of the options.

\section{Concluding Remarks}

This paper indicates that bond rates are the primary transmission channel for monetary policy, and that bond rates contain both averages of trader expectations of future short rate actions by the central bank and term premiums reflecting trader uncertainty regarding future policy.

In periods of routine fluctuations in economic activity and inflation, monetary policy appears to function well by setting the current level of the short rate. Given that future shocks to macroeconomic indicators are unknown, bond traders will discount policy announcements that the central bank is pre-committed to a fixed path of real or nominal interest rates.

However, in situations where policy responses are apt to be less predictable, the central bank may wish to tighten connections between bond rates and the short rate. The example discussed in this paper is when the average level of interest rates is low, due to the perception that long-run inflation is near zero, and there is little room for extensive signaling by the central bank with the short rate. The credibility of signaling regarding near-term movements in the short rate is apt to be improved if the central bank trading desk writes put options on Treasury bonds.

Illustrations used in the previous section were simple European options on forward interest rates at a single point in time. The trading desk can write more complex options that insure against deviations of the short rate from a prescribed trajectory over a given horizon. For example, firms and households are likely to make decisions on the basis of average interest rates over a planning 
period, not interest rates at particular points in time such as specified in the European put examples. One alternative is for the trading desk to write average-value options where the owner of the option is compensated for average deviations from strike prices or rates over the length of the option rather than for the differential that exists only at the option expiration date. Because the volatility of time averages is smaller than the volatility at a single date, the cost of private sector insurance against unexpected policy is also smaller. ${ }^{28}$

Discussion in this paper has been confined to policy use of derivatives on government securities. Subject to constraints on admissible central bank trading, it may be useful to explore the potential for policy derivatives to reduce other sources of uncertainty that may confront firms and households during periods of severe market stress, such as an unusual disruption of credit markets. The potential flexibility of options contracts suggests that policy derivatives can be a versatile addition to the toolkit of central banks.

\footnotetext{
${ }^{28}$ For valuations of average-value options, see Turnbull and Wakemann (1991) and discussion of so-called "Asian" options in Hull (1997).
} 


\section{References}

Bernanke, B., and A. Blinder, 1992, "The Federal Funds Rate and the Channels of Monetary Transmission," American Economic Review, 82(4), September, 901-21.

Black, F. 1976. “The Pricing of Commodity Contracts.” Journal of Financial Economics, 3, January/March, 167-79.

Brenner, R., R. Harjes, and K. Kroner, 1996, "Another Look at Models of the Short-Term Interest Rate," Journal of Financial and Quantitative Analysis, 31, 85-107.

Cecchetti, S., 1988. "The Case of the Negative Nominal Interest Rates: New Estimates of the Term Structure of Interest Rates during the Great Depression." Journal of Political Economy, 96, December, 1111-41.

Cox, J, J. Ingersoll, and S. Ross, 1985. "A Theory of the Term Structure of Interest Rates." Econometrica, 53, March, 385-407.

Fedenia, M. and T. Grammatikos. 1992. "Options Trading and the Bid-Ask Spread of the Underlying Stocks.” Journal of Business, 65, July, 335-51.

Friedman, M. and A. Schwartz. 1963, A Monetary History of the United States, 1867-1960." Princeton University Press: Princeton.

Fuhrer, J. and B. Madigan. 1997. "Monetary Policy when Interest Rates are Bounded at Zero." Review of Economics and Statistics, 79, November, 573-85.

Hull, J. 1997. Options, Futures, and Other Derivatives, 3rd edition, Upper Saddle River,NJ: Prentice-Hall.

Miltersen, K., K. Sandmann, and D. Sondermann. 1997. "Closed Form Solutions for Term Structure Derivatives with Log-Normal Interest Rates." Journal of Finance, 52, March, 409-30.

Johnson, N. and S. Kotz. 1970. Continuous Univariate Distributions, New York: John Wiley.

Keynes, J. 1930. A Treatise on Money, vol. II, London: Macmillan.

Kozicki, S., D. Reifschneider, and P. Tinsley. 1996. “The Behavior of Long-Term Interest Rates in the FRB/US Model," in The Determination of Long-Term Interest Rates and Exchange Rates and the Role of Expectations, Basle: Bank for International Settlements, 215-50.

Kozicki, S. and P. Tinsley. 1996. "Moving Endpoints and the Internal Consistency of Agents; Ex Ante Forecasts.” Computational Economics, 11, April, 21-40.

Kozicki, S. and P. Tinsley. 1998. “Term Structure Views of Monetary Policy.” Federal Reserve Board/Federal Reserve Bank of Kansas City staff working paper.

Laxton, D. and E. Prasad. 1997. "Possible Effects of European Monetary Union on Switzerland: A Case Study of Policy Dilemmas caused by Low Inflation and the Nominal Interest Rate Floor," IMF Working Paper, WP/97/23.

Macaulay, F. 1938. The Movements of Interest Rates, Bond Yields and Stock Prices in the 
United States since 1856, National Bureau of Economic Research: New York.

McCulloch, H., 1975, "The Tax-Adjusted Yield Curve," The Journal of Finance, 30, June, 811-30.

McCulloch, H. and H. Kwon, 1993, “U.S. Term Structure Data, 1947-1991,” Ohio State University Working Paper 93-6, March.

Merton, R. 1973. “An Intertemporal Capital Asset Pricing Model," Econometrica, 41, September, 867-87.

Merton, R. 1995. "Financial Innovation and the Management and Regulation of Financial Institutions," Journal of Banking and Finance, 19, June, 461-81.

Mullins, D. 1997. "Challenges for Monetary Policy in the Evolving Financial Environment," in I. Kuroda (ed.) Towards More Effective Monetary Policy, New York: St. Martin's Press, 99-129.

Orphanides, O. and V. Wieland. 1998. "Price Stability and Monetary Policy Effectiveness when Nominal Interest Rates are Bounded at Zero." FRB staff working paper.

Taylor, J. 1993. "Discretion versus Policy Rules in Practice," in A. Meltzer and C. Plosser (eds.) Carnegie-Rochester Conference Series on Public Policy, 39, Amsterdam: North-Holland, 195-214.

Tetlow, R. and J. Williams. 1998. "Implementing Price Stability: Bands, Bounds, and Inflation Targeting." FRB staff working paper.

Turnbull, S. and L. Wakeman. 1991. "A Quick Algorithm for Pricing European Average Options." Journal of Financial and Quantitative Analysis, 26, September, 377-89.

U.S. Bureau of the Census. 1975. Historical Statistics of the United States, Washington D.C.: U.S. Government Printing Office. 
Table 1: Output Deviations from Trend ${ }^{a}$

$$
y_{t}=c_{0}+c_{1} y_{t-1}+c_{2}(L) \Delta y_{t-1}+c_{3} \rho_{x, t-1}+c_{4}(L) \Delta \rho_{x, t-1}+c_{5} \rho_{z, t-1}+c_{6}(L) \Delta \rho_{z . t-1}+a_{t} .
$$

\begin{tabular}{|c|c|c|c|c|c|c|c|c|}
\hline real rate & $c_{1}$ & $c_{2}$ & $c_{3}$ & $c_{4}$ & $c_{4}$ & $c_{4}$ & $S E E$ & $\overline{\rho_{x}}{ }^{b}$ \\
\hline$\rho_{x}=\rho_{1}$ & $\begin{array}{c}.966 \\
(109.6)\end{array}$ & $\begin{array}{l}.577 \\
(7.9)\end{array}$ & $\begin{array}{l}-.027 \\
(-1.6)\end{array}$ & $\begin{array}{l}.107 \\
(1.4)\end{array}$ & & & .651 & $\begin{array}{l}1.37 \\
(1.1)\end{array}$ \\
\hline$\rho_{x}=\rho_{60}$ & $\begin{array}{c}.956 \\
(100.9)\end{array}$ & $\begin{array}{l}.505 \\
(6.9)\end{array}$ & $\begin{array}{c}-.102 \\
(-3.7)^{* * *}\end{array}$ & $\begin{array}{l}.235 \\
(1.2)\end{array}$ & & & .625 & $\begin{array}{c}3.23 \\
(10.0)\end{array}$ \\
\hline $\begin{array}{l}\rho_{x}=\rho_{60} \\
\rho_{z}=\rho_{1}-\rho_{60}\end{array}$ & $\begin{array}{c}.956 \\
(99.9)\end{array}$ & $\begin{array}{l}.483 \\
(6.4)\end{array}$ & $\begin{array}{c}-.105 \\
(-3.8)^{* * * *}\end{array}$ & $\begin{array}{l}.226 \\
(1.1)\end{array}$ & $\begin{array}{r}-.028 \\
(-1.4)\end{array}$ & $\begin{array}{l}.080 \\
(0.9)\end{array}$ & .626 & \\
\hline$\rho_{x}=\rho_{120}$ & $\begin{array}{c}.962 \\
(107.3)\end{array}$ & $\begin{array}{l}.511 \\
(6.9)\end{array}$ & $\begin{array}{c}-.116 \\
(-3.3)^{* * *}\end{array}$ & $\begin{array}{l}.170 \\
(0.7)\end{array}$ & & & .627 & $\begin{array}{c}3.50 \\
(12.8)\end{array}$ \\
\hline $\begin{array}{l}\rho_{x}=\rho_{120} \\
\rho_{z}=\rho_{1}-\rho_{120}\end{array}$ & $\begin{array}{c}.963 \\
(105.9)\end{array}$ & $\begin{array}{l}.510 \\
(6.7)\end{array}$ & $\begin{array}{c}-.117 \\
(-3.3)^{* * * *}\end{array}$ & $\begin{array}{l}.183 \\
(0.8)\end{array}$ & $\begin{array}{l}.006 \\
(0.3)\end{array}$ & $\begin{array}{l}-.016 \\
(-0.2)\end{array}$ & .631 & \\
\hline $\begin{array}{l}\rho_{x}=\rho_{60} \\
\rho_{z}=\rho_{120}-\rho_{60}\end{array}$ & $\begin{array}{l}.955 \\
(95.7)\end{array}$ & $\begin{array}{l}.504 \\
(6.7)\end{array}$ & $\begin{array}{c}-.086 \\
(-2.1)^{* *}\end{array}$ & $\begin{array}{l}.167 \\
(0.7)\end{array}$ & $\begin{array}{l}.049 \\
(0.5)\end{array}$ & $\begin{array}{l}-.173 \\
(-0.3)\end{array}$ & .629 & \\
\hline $\begin{array}{l}\rho_{x}=\rho_{120} \\
\rho_{z}=\rho_{60}-\rho_{120}\end{array}$ & $\begin{array}{c}.955 \\
(95.7)\end{array}$ & $\begin{array}{l}.504 \\
(6.7)\end{array}$ & $\begin{array}{l}-.086 \\
(-2.1)^{* *}\end{array}$ & $\begin{array}{l}.167 \\
(0.7)\end{array}$ & $\begin{array}{l}-.134 \\
(-1.7)^{*}\end{array}$ & $\begin{array}{l}.340 \\
(0.7)\end{array}$ & .629 & \\
\hline
\end{tabular}

${ }^{a}$ In each regression, the dependent variable is monthly capacity utilization of manufacturing, $y$. Competing regressors are: 1-month real rate, $\rho_{1}=r_{1}-E_{t} \pi_{1} ; 5$-year real rate, $\rho_{60}=r_{60}-E_{t} \pi_{60}$; and 10-year real rate, $\rho_{120}=r_{120}-E_{t} \pi_{120}$. Polynomials in the lag operator, $L$, are fifth-order. The sample span is $1967 \mathrm{~m} 1-1997 \mathrm{~m} 9$. Confidence levels of $90 \%(*), 95 \%(* *)$, and $99 \%(* * *)$ are indicated for the boldface $t$-ratios.

${ }^{b}$ Entries in the last column, $\overline{\rho_{x}}$, denote "equilibrium" real rates, or levels of the real interest rate consistent with trend output growth at the mean rate of capacity utilization. 


\section{figure 1: VAR predictions of 1O-year bond rates}
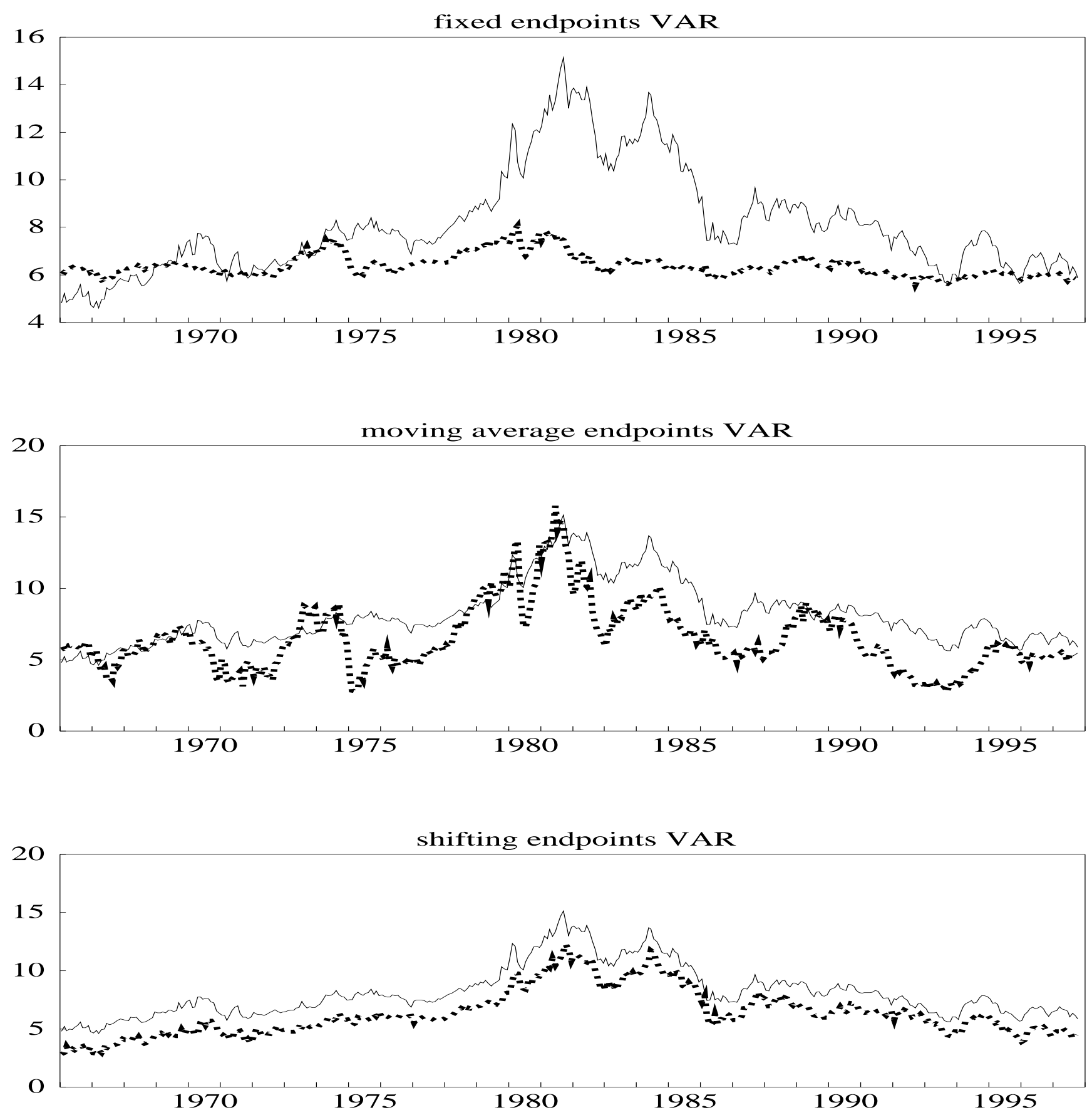

historical

..... predicted 


\section{Table 2: Regression Analysis of Residual Term Premiums ${ }^{a}$}

$$
\theta_{t}^{R}=c_{0}+c_{1} \hat{r}_{1 . t}+a_{t} .
$$

\begin{tabular}{|c|c|c|c|c|}
\hline $\begin{array}{l}\text { term premium } \\
\text { source }\end{array}$ & $c_{0}$ & $c_{1}$ & $R^{2}$ & $S E E$ \\
\hline \multirow[t]{2}{*}{$\begin{array}{l}\text { fixed } \\
\text { endpoint VAR }\end{array}$} & $\begin{array}{c}1.74 \\
(17.3)\end{array}$ & & & 1.95 \\
\hline & $\begin{array}{l}-1.98 \\
(-10.0)\end{array}$ & $\begin{array}{l}.575 \\
(20.0)\end{array}$ & .51 & 1.36 \\
\hline \multirow[t]{2}{*}{$\begin{array}{l}\text { moving average } \\
\text { endpoint VAR }\end{array}$} & $\begin{array}{l}1.68 \\
(20.8)\end{array}$ & & & 1.54 \\
\hline & $\begin{array}{c}2.87 \\
(13.5)\end{array}$ & $\begin{array}{l}-.190 \\
(-6.2)\end{array}$ & .09 & 1.47 \\
\hline \multirow[t]{2}{*}{$\begin{array}{l}\text { shifting } \\
\text { endpoint VAR }\end{array}$} & $\begin{array}{c}1.79 \\
(72.5)\end{array}$ & & & .486 \\
\hline & $\begin{array}{c}1.12 \\
(18.4)\end{array}$ & $\begin{array}{c}.103 \\
(11.6)\end{array}$ & .26 & .414 \\
\hline
\end{tabular}

${ }^{a} \theta^{R}$ denotes residual estimates of the term premiums for 10 -year bonds generated by the fixed, moving average, and shifting endpoint VARs. The regressors are predictions by the relevant VARs of the 1-month nominal interest rate, $\hat{r}_{1}$. The sample span is $1966 \mathrm{~m} 1-1997 \mathrm{~m} 9$. 
Table 3: Level-Based Estimates of Conditional Variances of One-Month Bond Rate. ${ }^{a}$

$$
u_{r, t}^{2}=\phi_{0}+\phi_{1} \hat{r}_{t}+a_{t}
$$

\begin{tabular}{|c|c|c|}
\hline $\begin{array}{l}\text { residual } \\
\text { source }\end{array}$ & $\phi_{1}$ & $S E E$ \\
\hline $\begin{array}{l}\text { fixed endpoints } \\
\text { VAR }\end{array}$ & $\begin{array}{l}.237 \\
(9.3)\end{array}$ & 1.21 \\
\hline $\begin{array}{l}\text { moving average } \\
\text { endpoints VAR }\end{array}$ & $\begin{array}{l}.240 \\
(9.6)\end{array}$ & 1.19 \\
\hline $\begin{array}{l}\text { shifting } \\
\text { endpoints VAR }\end{array}$ & $\begin{array}{l}.241 \\
(9.6)\end{array}$ & 1.18 \\
\hline
\end{tabular}

${ }^{a} u_{r, t}$ denotes the one-period forecast error of $r_{t}$ and $\hat{r}_{t}$ the one-period forecast of the one-month rate. Forecasts are generated by 6-order, monthly VARs in $r, \pi$, and $y$ with fixed, moving-average, or shifting endpoints. The sample span is $1966 \mathrm{~m} 1-1997 \mathrm{~m} 9$. 


\section{figure 2: Estimates of 10-year bond rate term premiums}
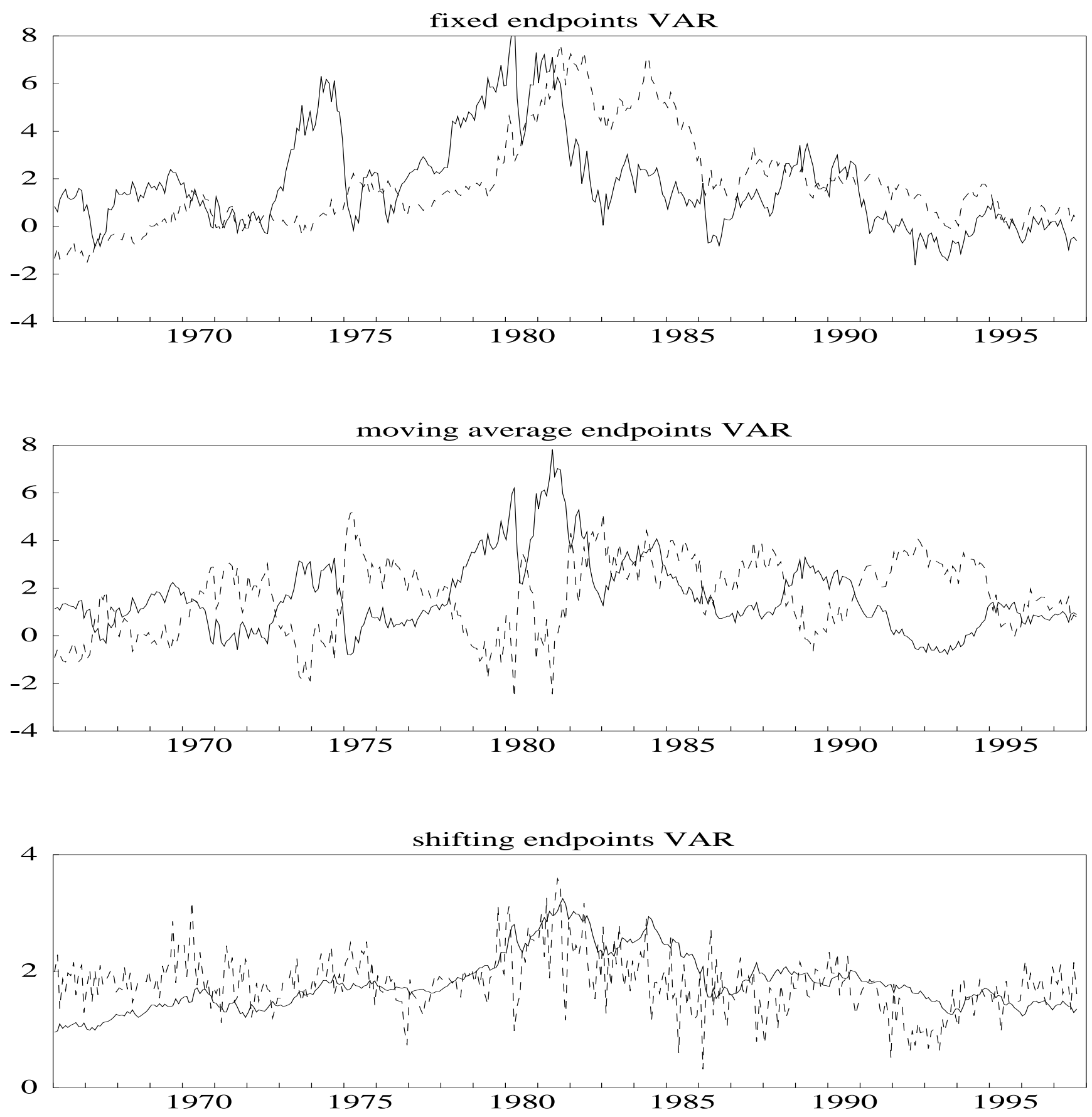

- - residual-based estimate

theory-based construction 
Figure 3: Alternative Short Rate Expectations subject to the Zero Boundary

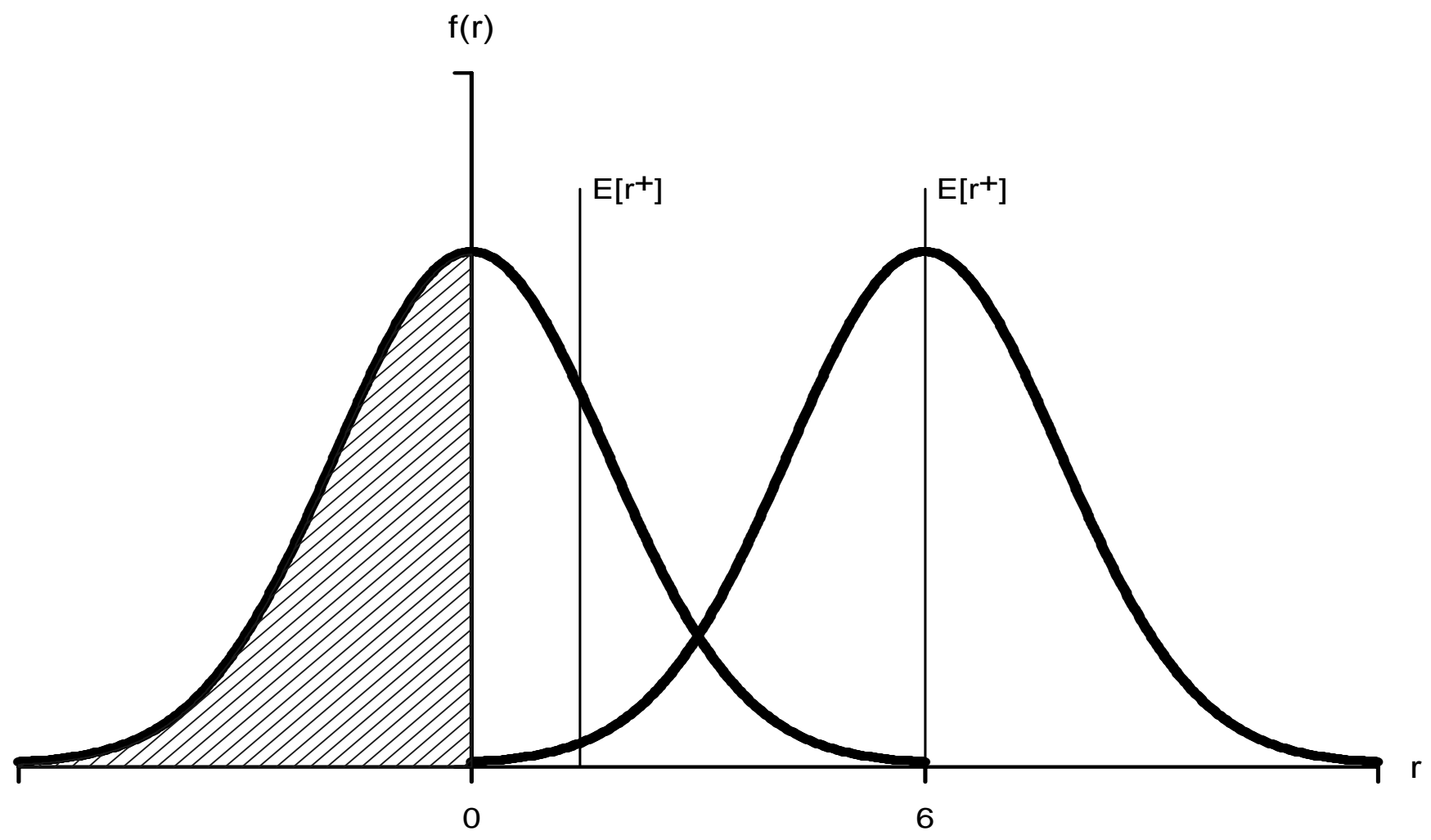


Table 4: Effects of Short Rate Uncertainty and the Zero Bound on Expected Interest Rates

alternative short rate assumptions ${ }^{a}$

certainty equivalent expectation, $E\left\{r_{1}\right\}$

6.0

4.0

2.0

0.0

standard deviation, $\sigma_{1}$

1.80

1.80

1.80

1.80

expectation under zero bound, $E\left\{r_{1}^{+}\right\}$

6.00

4.06

2.45

1.44

components of 5-year bond rate:

expected short rate average, $\frac{1}{60} \sum_{i=0}^{59} E\left\{r_{1, t+i}^{+}\right\}$

$6.00 \quad 4.06 \quad 2.45$

1.44

term premium, $\theta_{60, t}$

$2.14 \quad 1.73$

1.40

1.19

total, $r_{60, t}^{+}$

8.14

5.80

3.85

2.63

additional assumption: initial month at zero (nondeterministic), $r_{t}=0$.

expected short rate average, $\frac{1}{60} \sum_{i=0}^{59} E\left\{r_{1, t+i}^{+}\right\}$

5.92

4.02

2.43

1.44

term premium, $\theta_{60, t}$

2.11

1.72

1.39

1.19

total, $r_{60, t}^{+}$

8.04

5.74

3.83

2.63

additional assumptions: initial 12 months at zero (nondeterministic), $r_{1, t+i}=0(i=0, \ldots, 11)$.

expected short rate average, $\frac{1}{60} \sum_{i=0}^{59} E\left\{r_{1, t+i}^{+}\right\}$

5.09

3.53

2.25

1.44

term premium, $\theta_{60, t}$

1.88

1.59

1.34

1.19

total, $r_{60, t}^{+}$

6.97

5.13

3.59

2.63

additional assumptions: initial 12 months at zero (deterministic), $r_{1, t+i}=\sigma_{1, t+i}=0(i=0, \ldots, 11)$.

expected short rate average, $\frac{1}{60} \sum_{i=0}^{59} E\left\{r_{1, t+i}^{+}\right\}$

4.80

3.25

1.96

1.15

term premium, $\theta_{60, t}$

1.63

1.33

1.08

0.93

total, $r_{60, t}^{+}$

6.43

4.58

3.04

2.08

additional assumptions: initial 24 months at zero (deterministic), $r_{1, t+i}=\sigma_{1, t+i}=0(i=0, \ldots, 23)$.

expected short rate average, $\frac{1}{60} \sum_{i=0}^{59} E\left\{r_{1, t+i}^{+}\right\} \quad 3.60$

term premium, $\theta_{60, t}$

1.13

4.73

2.44

1.47

0.86

total, $r_{60, t}^{+}$

0.94

0.78

0.68

1.54

${ }^{a}$ For the sample $1982 \mathrm{~m} 10-1997 \mathrm{~m} 9$, the mean and standard deviation of the 1 -month zero-coupon rate were 6.06 and 1.80 , respectively. 
Table 5: Hypothetical 3-Month Call Options on the Forward 9-Month Rate ${ }^{a}$

$$
\begin{aligned}
\operatorname{call}_{t}\left(r_{9, t+2}, r_{x}\right) & =E_{t}\left\{M_{t+2}\left(r_{9, t+2}-r_{x}\right)^{+}\right\} . \\
& =e^{-r_{3, t} / 400}\left(E_{t}\left\{r_{9, t+2}\right\} N\left(d_{1}\right)-r_{x} N\left(d_{2}\right)\right) .
\end{aligned}
$$

\begin{tabular}{|c|c|c|c|c|}
\hline & \multicolumn{4}{|c|}{ alternative forward rate assumptions $s^{b}$} \\
\hline $\begin{array}{l}\text { forward 9-month rate, } E_{t}\left\{r_{9, t+2}\right\} \\
\text { standard deviation of } \log \text { forward rate, } \sigma_{9, t+2} \\
\text { current 3-month rate, } r_{3, t} \\
\text { discount factor, } e^{-r_{3, t} / 400}\end{array}$ & $\begin{array}{l}6.0 \\
.312 \\
6.00 \\
.985\end{array}$ & $\begin{array}{l}4.0 \\
.312 \\
6.00 \\
.985\end{array}$ & $\begin{array}{l}2.0 \\
.312 \\
6.00 \\
.985\end{array}$ & $\begin{array}{l}0.1 \\
.312 \\
6.00 \\
.985\end{array}$ \\
\hline alternative strike rates: & \multicolumn{4}{|c|}{ call option values } \\
\hline$r_{x}=6.0$ & .732 & .068 & 0.0 & 0.0 \\
\hline$r_{x}=4.0$ & 2.038 & .488 & .004 & 0.0 \\
\hline$r_{x}=2.0$ & 3.940 & 1.974 & .244 & 0.0 \\
\hline$r_{x}=0.1$ & 5.812 & 3.842 & 1.872 & .012 \\
\hline
\end{tabular}

${ }^{a} M_{t+2}$ denotes the stochastic valuation factor for yields payable in three months; the "+" superscript selects only positive values; and $\mathrm{N}\left(\right.$. ) indicates the cumulative distribution function for the normal distribution. The $d_{1}$ and $d_{2}$ arguments are defined in the text.

${ }^{b}$ For the sample $1982 \mathrm{~m} 10-1997 \mathrm{~m} 9$, means of the 3-month zero coupon rate and the forward 9-month rate were about 6.3 and 7.0. The standard deviation of the forward 9-month $\log$ rate was approximately .312. 